Review

\title{
Does depression predict the use of urgent and unscheduled care by people with long term conditions? A systematic review with meta-analysis
}

\author{
Chris Dickens ${ }^{a, b, *}$, Wayne Katon ${ }^{c}$, Amy Blakemore ${ }^{\mathrm{d}}$, Angee Khara ${ }^{\mathrm{d}}$, Linda McGowan ${ }^{\mathrm{e}}$, Barbara Tomenson ${ }^{\mathrm{f}}$, \\ Judy Jackson ${ }^{\mathrm{d}}$, Liz Walker ${ }^{\mathrm{d}}$, Else Guthrie ${ }^{\mathrm{d}}$ \\ a Mental Health Research Group, Peninsula College of Medicine and Dentistry, University of Exeter, UK \\ ${ }^{\mathrm{b}}$ National Institute for Health Research (NIHR) Collaboration for Leadership in Applied Health Research and Care (CLAHRC) for the South West Peninsula (PenCLAHRC), UK \\ c Department of Psychiatry and Behavioral Sciences, University of Washington, USA \\ d Department of Psychiatry, Manchester Mental Health and Social Care Trust, UK \\ e School of Nursing, Midwifery and Social Work, University of Manchester and Manchester Academic Health Sciences Centre, UK \\ ${ }^{\mathrm{f}}$ Psychiatry Research Group, School of Community Based Medicine, University of Manchester, and Manchester Academic Health Sciences Centre, UK
}

\section{A R T I C L E I N F O}

\section{Article history:}

Received 14 May 2012

Received in revised form 4 July 2012

Accepted 27 August 2012

\section{Keywords:}

Depression

Long term conditions

Urgent healthcare utilisation

Systematic review

Meta analysis

\begin{abstract}
A B S T R A C T
Background: Factors that drive the use of urgent healthcare among people with chronic physical illness (i.e. long term conditions-LTCs) are poorly understood. We conducted a systematic review with meta analysis to examine the strength of association between depression and subsequent use of urgent healthcare among people with LTCs.

Methods: Electronic searches of MEDLINE, EMBASE, PSYCINFO, CINAHL, the British Nursing Library and the Cochrane Library 2011 were conducted, supplemented by hand-searching bibliographies, citation tracing eligible studies and asking experts about relevant studies. Studies were eligible for inclusion if they: i)used prospective cohort design, ii)included patients with diabetes, asthma, chronic obstructive pulmonary disease or coronary heart disease, iii)used a standardised measure of depression, and iv)assessed urgent healthcare utilisation prospectively. Data on the subjects recruited, methods used and the association between depression and subsequent urgent healthcare utilisation were extracted from eligible studies. Odds ratios (ORs) were calculated for each study and pooled using random effects models.

Results: 16 independent studies were identified. Pooled effects indicated that depression was associated with a $49 \%$ increase in the odds of urgent healthcare utilisation $(\mathrm{OR}=1.49, \mathrm{p}<.0005)$. This effect was not significantly affected by publication bias or inclusion of studies of low quality. Effects were much smaller and non-significant among the 3 studies that controlled for other covariates, including severity of illness $(\mathrm{OR}=1.13, \mathrm{p}=.31)$.

Conclusions: Depression was associated with increased urgent healthcare use, but not in the minority of studies that controlled for other covariates. This possibly suggests confounding, but the severity measures may themselves have been influenced by depression.
\end{abstract}

Crown Copyright @ 2012 Published by Elsevier Inc. All rights reserved.

\section{Introduction}

Chronic physical illnesses, or long term conditions (LTCs) as they are also known, are common in the general population and are associated with considerable costs to affected individuals and healthcare providers alike. In the UK, one third of the population suffer from long term conditions, of whom approximately half will experience significant disability [1]. In the United States alone, LTCs such as heart disease, diabetes and chronic lung disease affect 133 million individuals (2005 figure),

Abbreviations: COPD, chronic obstructive pulmonary disease; $\mathrm{CHD}$, coronary heart disease; LTCs, long term conditions; OR, odds ratio.

* Corresponding author at: Mental Health Research Group, Institute of Health Service Research, Peninsula College of Medicine and Dentistry, Universities of Exeter and Plymouth, Veysey Building, Salmon Pool Lane, Exeter EX2 4SG, UK. Tel.: + 441392726013 .

E-mail address: chris.dickens@pcmd.ac.uk (C. Dickens). and account for $\$ 0.7$ trillion of annual healthcare expenditure (i.e. $70 \%$ of total expenditure) [2-4]. Globally, long term conditions accounted for 36 million of the 57 million deaths in 2008 [5]. Furthermore, the prevalence of LTCs is set to increase due to ageing of the population and unhealthy lifestyle choices, with an anticipated prevalence of 157 million in the US by 2020 [6]. Reducing the health burden and costs attributable to LTCs is a priority for economies of many developed countries.

People with LTCs commonly use urgent and unscheduled healthcare (henceforth urgent healthcare). Eight percent of people with asthma in the US made at least one visit to the emergency department (ED) over a 12 month period [7] and 13\% of patients with chronic obstructive pulmonary disease (COPD) made 6 or more visits [8]. Consequently, a considerable proportion of the healthcare costs in people with LTCs can be attributed to the use of expensive urgent healthcare. In a recent European study, urgent healthcare accounted for $56 \%$ of total costs in 
adults with asthma [9], regardless of the severity of patients' symptoms. Diverting LTC patients away from usual care and into more appropriate routine services has potential to substantially reduce healthcare costs of people with LTCs.

The factors that drive the use of urgent healthcare are not well understood, however. Such use could relate to the severity and unpredictability of the LTC; among asthma patients, a history of previous hospitalisations was associated with significantly increased risk of subsequent urgent healthcare use [10,11]. Other predictors of urgent healthcare might include being older, female, less educated or having other medical comorbidities [10,11]. Psychological factors may also be important in this respect, however. A quarter of all patients with LTCs have co-existing mental disorders, which have been associated with poorer health outcomes $[12,13]$, including greater healthcare utilisation $[14,15]$, greater healthcare costs [16] and more frequent use of accident and emergency department $[17,18]$. In diabetes specifically, depression has been associated with more emergency department visits ( 0.5 visits per person per year compared to 0.3 visits per person per year in the non-depressed) [19]. Among asthma patients depression was shown to predict increased use of urgent healthcare even after controlling for age and sex $[10,11]$. Not all studies have demonstrated that depression predicts increased urgent healthcare utilisation, however; [20,21]. This heterogeneity is probably attributable to variation in the types of patients recruited and the methodologies used, with the result that it remains unclear to what extent depression predicts increased use of urgent healthcare.

We have conducted a systematic review of the literature with meta analysis to clarify the extent to which depression predicts the subsequent use of urgent healthcare among people with LTCs. We hypothesised that depressed patients with LTCs would use significantly more urgent care. Clarification of this association is important, since treatments that target depression could have potential to reduce the use of urgent healthcare and associated healthcare costs.

\section{Method}

Studies were eligible for inclusion in the review if they met the following criteria.

\section{a) Prospective cohort design}

b) Included adults with one or more of the following LTCs: diabetes (any type), asthma or COPD (acute or chronic) or CHD (myocardial infarction, stable or unstable angina)

c) Used a standardised measure of depression at baseline

d) Assessed urgent healthcare utilisation prospectively.

Rather than attempt to identify literature on all LTCs, we focused on these 4 exemplar conditions that not only account for considerable illness burden, but also are associated with high rates of psychological morbidity. These conditions represent 3 of the top 4 most burdensome non-communicable diseases worldwide [22]; they have been shown to be among the most common discharge diagnoses from emergency departments [23] and have been associated with emergency hospital admissions [24]. We excluded patients with cancer (the other noncommunicable disease in the WHO's top 4) since this disease category is very heterogeneous, not all such patients can be regarded as suffering from a LTC $^{1}$ and patients with cancer tend to use urgent care less than individuals with our chosen disorders $[23,24]$.

For the purposes of this review, we did not limit studies included by way depression was assessed or the types of urgent care recorded, to maximise capture of relevant data. Studies could be included, provided assessment of depression was standardised and that urgent healthcare was definitely urgent either i) by the very nature of the care recorded

\footnotetext{
${ }^{1}$ The Department of Health in the UK defines long term conditions as being incurable but manageable with treatment/therapy.
}

(e.g. accident and emergency clinic attendance or urgent general practitioner visits or ii) where it was explicitly described in the study report that care was urgent or unscheduled. Hospitalisation, for example, could be urgent or non-urgent. In this review, hospitalisations were only considered urgent if they were described as such in the published paper, if hospitalisations were described as being the result of an acute exacerbation of underlying LTC or if researchers, when contacted, confirmed that hospitalisations were urgent.

Studies were not excluded by date or language of publication, sample size or follow up period. Unpublished studies and those published in abstract form only were not included in this review, since i) it can be difficult to ensure unpublished papers are typical of other papers (published or unpublished), ii) unpublished papers can be of lower methodological quality and iii) authors can be reluctant to release additional data from studies that are unpublished. Instead we chose to include published papers only, but to investigate in detail the effects of publication bias on our findings. See appendix (page 2) for full inclusion and exclusion criteria.

Electronic search strategies were developed in-team, in consultation with librarians with experience of performing systematic reviews. Search strategies were peer reviewed by experts from within the University of Manchester and modified accordingly. Search strategies included terms relevant to the LTCs of interest and were limited to prospective studies (see pages 3 to 14 in the appendix for details of search strategies used). To maximise sensitivity, electronic searches were used to identify studies investigating a broad range of psychosocial factors; the subgroup of papers including standardised measures of depression were identified by hand searching potentially eligible papers. We were not able to develop sensitive and reliable strategies to identify studies investigating use of urgent healthcare specifically, so searches were developed to identify all healthcare utilisation and further restriction to relevant papers was achieved by hand searching potentially eligible papers.

Searches were conducted in MEDLINE, EMBASE, PSYCHINFO, CINAHL, The British Nursing Index (using the OVID search interface) and the Cochrane Library, from inception of each database. Electronic searches were first conducted on 19th August 2008 and then updated on 16th December 2009, 7th October 2011 and June 22nd 2012. Electronic searches were supplemented by hand searches of reference list of papers meeting inclusion criteria and relevant reviews identified through searching electronic databases. In addition relevant papers were citation searched using the Social Science Citation Index and authors of included papers were emailed to enquire whether they were aware of other studies. Titles and abstracts of papers identified by these means were screened by one of 3 researchers (JJ, AK and AB) to identify studies potentially meeting the inclusion criteria. Full text reports of studies that were potentially relevant to this review were screened to determine eligibility. To avoid double counting studies, findings for any population presented in multiple publications were included only once in this review (see p. 15 of the appendix for details of studies with multiple publications).

Further information was requested from authors of 33 papers of whom 28 responded and provided additional information on their papers. See Fig. 1 for a summary of the study selection process. Additional information provided by authors can be found in the appendix (pages 16-17).

\section{Data extraction}

Standardised data extraction sheets were developed by the team and modified after piloting on the first 5 papers. Data were extracted for characteristics of the participants, the measure of depression, the methodological characteristics of the study, the measure of unscheduled care and the strength of the association between depression and the use of unscheduled care. Multivariable and univariate associations are presented where both were reported in the papers. For the 

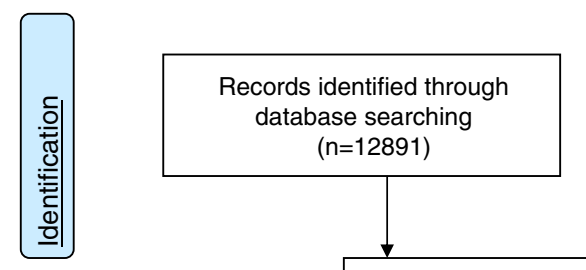

Additional records identified through other sources(searching reference lists and citation searching included paper $(n=12891)$ $(n=1914)$
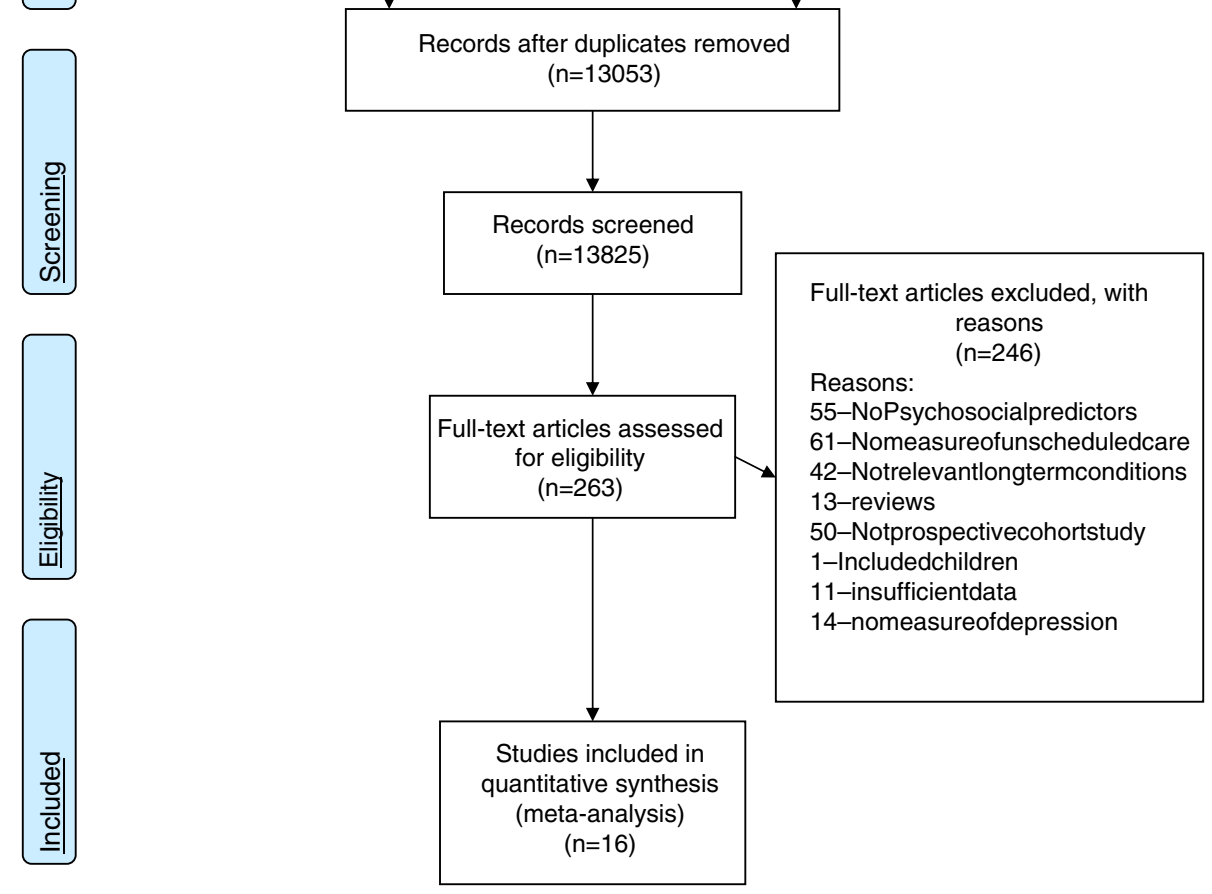

Fig. 1. PRISMA 2009 flow diagram.

meta analysis, where effect of depression on use of unscheduled care was presented in multiple formats, the least controlled data were used to generate effect sizes. Where available, effect sizes from multivariable analyses, that controlled for severity of the LTC, are presented and pooled for comparison with univariate effects.

Primary data extraction was performed by one of two researchers (JJ, EW), with discussion between researchers and another member of the team (CD) where there was uncertainty in any aspect of data interpretation or extraction. To check accuracy of the data extraction process, $20 \%$ of the papers were coded independently by both researchers. On comparison of data extraction sheets from each research there was $97 \%$ agreement.

\section{Risk of bias in individual studies}

The methodological quality of the individual studies was assessed using the Quality Assessment Tool for Quantitative Studies [14,15], based on whether:

i) There was an absence of selection bias of participants

ii) The study design was appropriate

iii) Confounding factors were adequately controlled

iv) Assessors were blind to depression status and subjects were blind to the research question.

v) Data collection methods were valid and reliable

vi) Withdrawal and drop-outs of subjects were adequately dealt with

vii) Analytical methods were appropriate. ${ }^{2}$

\footnotetext{
${ }^{2}$ The item of quality assessment relating to the integrity of interventions was excluded from this assessment.
}

Quality was assessed by two researchers independently with consensus being reached on discussion where discrepancies in assessments were found.

\section{Statistical analysis}

Odds ratios (O.R.) and 95\% confidence intervals (95\% CIs) were extracted ( 3 studies) or calculated for each study where number of subjects using unscheduled care with and without depression and the total number of subjects in each group were presented ( 6 studies). ORs $>1$ indicated that depression was associated with increased use of unscheduled care. Where data were presented in alternative formats [e.g. where studies presented results as continuous data ( 5 studies), as p-values for comparisons across groups with groups sizes (1 study), or as a correlation between depression and urgent healthcare use (1 study)] appropriate transformations were made using Comprehensive Meta analysis software (version 2.2.048, Nov 7th 2008) (see pages 18-19 of the appendix for transformation formulae).

In cases where follow-up data were collected at multiple time points, ORs were calculated for the follow-up data collected nearest to 1 year to maximise consistency across studies. Where studies included two measures of urgent healthcare, ORs for each measure were averaged, so that each independent study contributed a single effect to the meta analysis [25]. ORs for depression were combined across independent studies using the DerSimonian and Laird random effects method [26]. Heterogeneity among studies was assessed using Cochrane $\mathrm{Q}$ and $\mathrm{I}^{2}$ statistic $[27,28]$. Publication bias was assessed using an enhanced contour funnel plot Eggers' regression method, Peters regression method and Failsafe $\mathrm{N}$ - i.e. the number of additional negative studies that would be required to make the results of our meta analysis non-significant [29-32]. We used Duval and Tweedie's trim and fill procedure to correct for the effects of studies missing due to publication bias [33]. 
Effects for depression are presented in text and forest plot.

Meta analyses were performed using Comprehensive Meta-analysis (version 2.2.048, Nov 7th 2008) and Stata (version 11, StataCorp LP, Texas, USA).

\section{Results}

Sixteen independent studies were identified that met the criteria for inclusion [11,20,21,34-46], providing data from 8477 patients with LTCs (range $n=45$ to 1941) (see Table 1 for characteristics of studies included). Three studies were conducted in the US, 3 in Canada, 2 in Iran and one each in Germany, Spain, Nordic countries (Denmark, Norway, Finland, Sweden and Iceland), China, Japan, Singapore, Slovenia and Portugal Prospective cohort studies included patients with CHD $(n=5)[38,39,41,42,46]$, COPD $(n=8)[20,21,36,37,40,43-45]$, asthma $(n=2)[11,35]$ and diabetes $(n=1)[34]$.

Depression was assessed using self-rated questionnaires in all studies. In 11 of the 16 studies depression was treated as a categorical construct $[11,20,21,34,35,38-43]$. In one study only, depression equated with DSM-IV major depression [11]; in others depression was measured as a continuous variable. Measures of unscheduled care included in eligible studies included ED visits or ED costs $(n=4)[34,39,42,46]$ and confirmed urgent hospital admissions $(n=10)[11,20,35-38,40,41,43-45]$. One study combined ED visits and urgent hospitalisations as a composite measure of urgent care [21] and one study provided data on urgent hospital admissions and urgent general practitioner visits [11].

Of the 16 studies, 8 showed significant effects of depression on use of urgent healthcare [21,37-43] and 2 showed near significant effects $(p<.1)[35,45]$. The effects for the independent studies are presented in the forest plot (Fig. 2). The combined effect (OR) for depression across all studies was 1.49 (95\% CI 1.35-1.64), $\mathrm{p}<.0005$. Effects of individual studies were very homogeneous $\left(\mathrm{Q}=13.2, \mathrm{p}=.58, \mathrm{I}^{2}=0.0,95 \% \mathrm{CI}=0.52\right)$.

Effects varied across different types of urgent care: ED visits or $\mathrm{ED}$ costs $[\mathrm{n}=4, \mathrm{OR}=$ $1.45(95 \%$ Cl $1.26,1.66), \mathrm{p}<.0005]$, urgent hospitalisations $[\mathrm{n}=10, \mathrm{OR}=1.56(95 \% \mathrm{C}$ $1.32,1.84), \mathrm{p}<.0005]$, combined urgent hospitalisations or $\mathrm{ED}$ visits $[\mathrm{n}=1, \mathrm{OR}=1.29$ $(95 \% \mathrm{CI} 0.90,1.86), \mathrm{p}=.17]$ and combined urgent hospitalisation and urgent GP visits $[\mathrm{n}=1, \mathrm{OR}=2.69(95 \% \mathrm{CI} 1.16,6.23) \mathrm{p}=.021]$. Comparison across groups using the analog of ANOVA revealed that these differences in effect size across different types of unscheduled care were not statistically significant $(\mathrm{Q}=2.9$, d.f. $=3, \mathrm{p}=.41)$.

Effects varied across different LTCs lasthma: $\mathrm{n}=2$, OR $=1.76$ (95\% CI 0.99, 3.12) $\mathrm{p}=.055 ; \mathrm{CHD}: \mathrm{n}=5, \mathrm{OR}=1.54$ (95\% CI 1.35, 1.76), $\mathrm{p}<.0005 ;$ COPD: $\mathrm{n}=8$, OR $=1.40$ (95\% CI 1.18, 1.66), $\mathrm{p}<.0005$; Diabetes: $\mathrm{n}=1, \mathrm{OR}=1.34$ (95\% CI 0.89, 2.01), $\mathrm{p}=.16$ ). Comparison across groups using the analog of ANOVA revealed that these differences in effect size across different long term conditions were not statistically significant $(\mathrm{Q}=$ 1.2 , d.f. $=3, p=.76$ )

\section{Multivariable analyses}

The extent to which studies controlled for potentially confounding covariates was very variable. Of the 16 studies, only eight reported conducting multivariable analyses that controlled for severity of LTC among other co-variates [20,21,36-38,40,42,46]. Not all presented details of the multivariable findings; 4 presented numerical results and 4 reported only whether depression contributed to the final multivariable model, or not. Based on the reported results of multivariable analyses that controlled for the severity of underlying physical illness, in 6 studies effects of depression did not contribute significantly to the multivariable model $[20,21,36,37,42,46]$, and in 2 effects were significant $[38,40]$ - see Table 2 for result of multivariable analyses.

The 4 studies presenting numerical results of the multivariable analyses that controlled for severity of illness used measures of severity of LTC including i) forced expiratory volume in $1 \mathrm{~s}$ (for COPD patients), ii) forced vital capacity (for COPD patients) and iii) whether individual had had an anterior MI (for CHD patients). Three of these studies performed survival analyses and presented data as hazards ratios (95\% CI) $[20,37,38]$ and one presented incidence rate ratios [40]. Combining the effects of the 3 studies using hazards ratios gave a pooled effect of $1.13[(95 \% \mathrm{CI}=0.89,1.44), \mathrm{p}=.31]$, compared to an unadjusted pooled effect of 1.67 ( $95 \% \mathrm{CI}=1.09-2.56)$ for these 3 studies. The incidence rate ratio (which cannot be combined with hazards ratios) presented in a single study was $1.72(1.04-2.85), \mathrm{p}=.03$.

\section{Risk of bias within individual studies}

Details of the quality of studies are presented in Table 3. Two studies only were rated as strong (i.e. no weak ratings) [20,37], 6 were rated as moderate (i.e. one weak rating) $[11,21,35,38,40,42]$ and 8 were rated as weak (i.e. 2 or more weak ratings) [34,36,39,41,43-46]. The meta analyses were repeated for the studies sub-grouped according to methodological quality and revealed the following effect sizes: methodologically strong studies $\mathrm{n}=2, \mathrm{OR}=1.46(95 \% \mathrm{CI}=0.82,2.58), \mathrm{p}=.20$, moderate studies $\mathrm{n}=6, \mathrm{OR}=1.53(95 \% \mathrm{Cl}=1.31,1.77), \mathrm{p}<.0005$ and weak studies $\mathrm{n}=8, \mathrm{OR}=1.47(95 \% \mathrm{CI}=1.26,1.72), \mathrm{p}<.0005$. Comparing effects across studies sub-grouped by methodological quality using the analog of ANOVA revealed no significant difference in the effect sizes $(Q=0.12$, $\mathrm{df}=2, \mathrm{p}=.94)$.

\section{Publication bias}

The contour enhanced funnel plot did appear asymmetrical, with a relative absence of small negative studies (Fig. 3), and Egger's regression method confirmed and association between Log OR and standard error of Log OR [Egger's intercept $=1.98$ ( $95 \%$ CI 0.22 to 3.74 ), $\mathrm{p}=$ .03]. To investigate whether this asymmetry was attributable to a correlation between $\log$ OR and standard error of Log OR [47] or not, we also performed Peters' test [31], which confirmed a significant association between Log OR and 1 /sample size [intercept $=0.34$ (95\% CI 0.26 , $0.42) \mathrm{p}<.001$ ], consistent with publication bias. Finally, calculation of failsafe $\mathrm{N}$ indicated that an additional 245 negative studies would need to have included in this review to make the results of our meta analysis non-significant.

The Duval and Tweedie trim and fill procedure created 5 imputed studies, giving a revised random effects combined odds ratio for depression across all studies of 1.41 (95\% CI 1.27-1.57). This is very slightly reduced compared with the original, but still highly significant $(\mathrm{p}<.001)$. The heterogeneity between studies is increased slightly, but still not significant $(\mathrm{Q}=22.9, \mathrm{df}=20, \mathrm{p}=.29)$.

The filled funnel plot for standard error of log (odds ratio) against $\log$ (odds ratio) with pseudo 95\% confidence limits shows a more symmetric data set with no evidence of publication bias (page 22 of online appendix).

\section{Discussion}

We conducted a systematic review with meta analysis to determine the strength of association between depression and subsequent urgent healthcare utilisation among people with LTCs. When univariate findings from 16 independent studies were combined, depression was associated with a $49 \%$ increase in the odds of subsequent urgent healthcare utilisation. Effects for depression were not statistically significantly different across different types of urgent healthcare utilisation nor across different LTCs. Our findings were not influenced by the inclusion of studies with low methodological quality or by publication bias. Among the few studies that presented multivariable analyses that controlled for important covariates, the effects were much smaller and non-significant $(\mathrm{OR}=1.13, \mathrm{p}=.31)$.

Our review has a number of strengths. First, we conducted extensive searches of key electronic databases and also asked experts in the area about potentially relevant studies to identify as many relevant studies as possible. Second, rather than rely on the development of electronic search strategies to identify papers relevant to the construct of urgent healthcare, we kept our electronic searches broad (i.e. searched all healthcare) and narrowed to the relevant papers using rigorous hand-searching. Third we did not limit the types of urgent healthcare included a priori though we were very rigorous in the exclusion of studies for which it was not absolutely clear that the use of healthcare was urgent. We believe that our methodological rigour in identifying papers that were definitely relevant contributed to the homogeneity of our findings. Finally, we did not limit our review by the date or language of publication, sample size or duration of follow-up to maximise the number of studies included. 
Table 1

Study characteristics

\begin{tabular}{|c|c|c|c|c|c|c|c|}
\hline 1st author and date & $\begin{array}{l}\text { Condition } \\
\text { of study }\end{array}$ & $\begin{array}{l}\text { Sample } \\
\text { size }\end{array}$ & $\begin{array}{l}\text { Mean age } \\
\text { (years) }\end{array}$ & $\begin{array}{l}\text { Males } \\
\%\end{array}$ & Sample & Depression measure & Urgent healthcare utilisation measure \\
\hline Fan et al. 2007 [23] & COPD & 603 & 66.5 yrs & $64.1 \%$ & $\begin{array}{l}\text { 603/611 eligible patients with moderate to } \\
\text { severe emphysema self referred or were } \\
\text { referred by a clinician at U.S. clinics to control } \\
\text { arm of a lung surgery trial (NETT) }\end{array}$ & $\begin{array}{l}\text { Beck Depression Inventory (scores }=/>10 \text { vs } \\
<10 \text { ) }\end{array}$ & $\begin{array}{l}\text { Hospital records for COPD related inpatient ad- } \\
\text { missions and emergency department (ED) visits } \\
\text { for } 1 \text { year }\end{array}$ \\
\hline Eisner et al. 2005 [36] & Asthma & 756 & 59.9 yrs & $29.8 \%$ & $\begin{array}{l}\text { All adults admitted to ITU with asthma plus } \\
\text { sample of all patients hospitalised (without ITU) }\end{array}$ & CES-D $(\geq 16=$ depressed $)$ & $\begin{array}{l}\text { ED visits and hospitalisations recorded from } \\
\text { hospital computerised records for } 12 \text { months }\end{array}$ \\
\hline Schneider et al. 2008 [21] & Asthma & 256 & $56.3 \mathrm{yrs}$ & $38.3 \%$ & $\begin{array}{l}\text { Consecutive patients with asthma consulting } \\
\text { GPs, Germany. . }\end{array}$ & $\begin{array}{l}\text { Validated German version of PHQ from which } \\
\text { derive DSM IV depressive disorder }\end{array}$ & $\begin{array}{l}\text { Patients' self report of urgent hospitalisations } \\
\text { and emergency hospital visits over } 1 \text { year }\end{array}$ \\
\hline Ng et al. 2007 [22] & COPD & 376 & $72.2 \mathrm{yrs}$ & $85.1 \%$ & $\begin{array}{l}\text { Eligible consecutive inpatients hospitalised for } \\
\text { COPD exacerbation in Singapore }\end{array}$ & $\begin{array}{l}\text { Chinese HADS ( }=/>8 \text { vs }<8 \text { on depression } \\
\text { Score) }\end{array}$ & $\begin{array}{l}\text { Patient self-report on urgent hospitalisation at } 6 \\
\text { and } 12 \text { months after discharge }\end{array}$ \\
\hline Almagro et al. 2005 [38] & COPD & 141 & $72.0 \mathrm{yrs}$ & $93 \%$ & $\begin{array}{l}\text { Eligible, consecutive patients on inpatient ward } \\
\text { for acute exacerbation of COPD over } 7 \text { months. }\end{array}$ & Yesavage Depression Scale (continuous) & $\begin{array}{l}\text { Clinical records checked for readmissions of } \\
24 \mathrm{~h} \text { or more over } 1 \text { year }\end{array}$ \\
\hline Gudmundsson et al. 2006 [37] & COPD & 416 & 69.2 yrs & $48.8 \%$ & Patients hospitalised with COPD exacerbation. & HADS depression score (continuous) & $\begin{array}{l}\text { Self reported hospitalisations for acute } \\
\text { exacerbations of COPD } 1 \text { year after discharge, } \\
\text { checked via hospital records. }\end{array}$ \\
\hline Lauzon et al. 2003 [39] & CHD & 550 & 60.0 yrs & $78.9 \%$ & $\begin{array}{l}\text { Consecutive patients approached after } \\
\text { admission in } 10 \text { coronary care units }\end{array}$ & Beck Depression Inventory ( $=/>10$ vs $<10$ ) & $\begin{array}{l}\text { Hospital admissions recorded after } 30 \text { days, } \\
6 \text { months \& } 1 \text { year by self report (postal } \\
\text { questionnaire) and chart review }\end{array}$ \\
\hline Frasure-Smith et al. 2000 [40] & CHD & 848 & 59.3 yrs & $69.0 \%$ & $\begin{array}{l}\text { Subjects were recruited to } 2 \text { separate studies - } \\
1 \text { prospective cohort study and } 1 \text { control arm of } \\
\text { RCT. All patients were post MI. }\end{array}$ & Beck Depression Inventory (=/>10 vs $<10$ ) & $\begin{array}{l}\text { ED visits (all cause) and associated costs for } \\
1 \text { year post discharge for MI }\end{array}$ \\
\hline Kurdyak et al. 2008 [43] & CHD & 1941 & $64.0 \mathrm{yrs}$ & $30.4 \%$ & $\begin{array}{l}\text { MI in-patients from } 53 \text { hospitals across Ontario } \\
\text { Canada. }\end{array}$ & $\begin{array}{l}\text { Depression questionnaire, based on Brief Carroll } \\
\text { Depression Rating Scale. }(5 \text { or more vs }<5 \text { ) }\end{array}$ & ED visits (all cause) \\
\hline Xu et al. 2008 [41] & COPD & 491 & $65.6 \mathrm{yrs}$ & $68.8 \%$ & $\begin{array}{l}\text { Patients with physician diagnosed COPD, at- } \\
\text { tending } 10 \text { general hospitals in Beijing China }\end{array}$ & $\begin{array}{l}\text { Mandarin Chinese HADS ( }=1>8 \text { vs }<8 \text { on De- } \\
\text { pression scale) }\end{array}$ & $\begin{array}{l}\text { Medical interventions were monitored by a } \\
\text { telephone administered questionnaire over } \\
12 \text { months. Hospitalisations confirmed by chart } \\
\text { review. }\end{array}$ \\
\hline Shiotani et al. 2002 [42] & CHD & 1086 & 63.6 yrs & $80.4 \%$ & $\begin{array}{l}\text { Eligible consecutive patients with AMI, directly } \\
\text { admitted or transferred to } 25 \text { collaborating } \\
\text { hospitals eligible. }\end{array}$ & $\begin{array}{l}\text { Zung Self-rating depression Scale. } \\
\text { Non-depressed }- \text { scores }<40 \text { : depressed }- \\
\text { scores }+/>40 \text {. }\end{array}$ & $\begin{array}{l}\text { Data on cardiac events } 12 \text { months following } \\
\text { discharge from hospital records \& telephone } \\
\text { interviews with patients and family } 12 \text { months } \\
\text { after baseline }\end{array}$ \\
\hline Ciechanowski et al. 2000 [35] & Diabetes & 350 & $61.3 \mathrm{yrs}$ & $44 \%$ & $\begin{array}{l}\text { Patients from a diabetes register of } 2 \text { primary } \\
\text { care clinics }\end{array}$ & $\begin{array}{l}\text { SCL-90 }(\mathrm{R}) \text { - scores divided into tertiles (low/ } \\
\text { medium/high) - low versus others used for } \\
\text { meta analysis }\end{array}$ & $\begin{array}{l}\text { ED visits for } 6 \text { months following questionnaire } \\
\text { assessments collected using general health } \\
\text { cooperative automated data }\end{array}$ \\
\hline Ghanei et al. 2007 [46] & COPD & 157 & $58.3 \mathrm{yrs}$ & $63 \%$ & Patients attending chest clinic & $\begin{array}{l}\text { Hospital Anxiety and Depression Scale } \\
\text { depression subscale used as continuous } \\
\text { measure }\end{array}$ & $\begin{array}{l}\text { Acute hospitalisation resulting from COPD } \\
\text { exacerbation }\end{array}$ \\
\hline Carneiro et al. 2010 [45] & COPD & 45 & 68 yrs & $84.4 \%$ & $\begin{array}{l}\text { Inpatients admitted due to exacerbation of } \\
\text { COPD }\end{array}$ & $\begin{array}{l}\text { Beck Depression Inventory used as continuous } \\
\text { scale }\end{array}$ & $\begin{array}{l}\text { Hospitalisation resulting from exacerbation of } \\
\text { COPD }\end{array}$ \\
\hline Farkas et al. 2010 [44] & COPD & 127 & 66 yrs & $79 \%$ & Hospital outpatients with COPD & CES-D scale used as continuous measure & $\begin{array}{l}\text { Hospitalisation resulting from exacerbation of } \\
\text { COPD }\end{array}$ \\
\hline Pishgoo 2011 [47] & CHD & 334 & 57.5 years & $67.8 \%$ & $\begin{array}{l}\text { Cardiology outpatients with } \geq 50 \% \text { stenosis in at } \\
\text { least } 1 \text { major coronary artery }\end{array}$ & $\begin{array}{l}\text { HADS depression scale - (Persian translated } \\
\text { and validated }\end{array}$ & Al cause ED visits \\
\hline
\end{tabular}

Abbreviations

BDI Beck Depression Inventory.

CES-D Centre for Epidemiological Studies Depression Scale.

COPD chronic obstructive pulmonary disease.

ED emergency department.

HADS Hospital Anxiety and Depression Questionnaire

PHQ Patient Health Questionnaire.

SCL-90® Revised version of the 90 item Symptom Check List. 


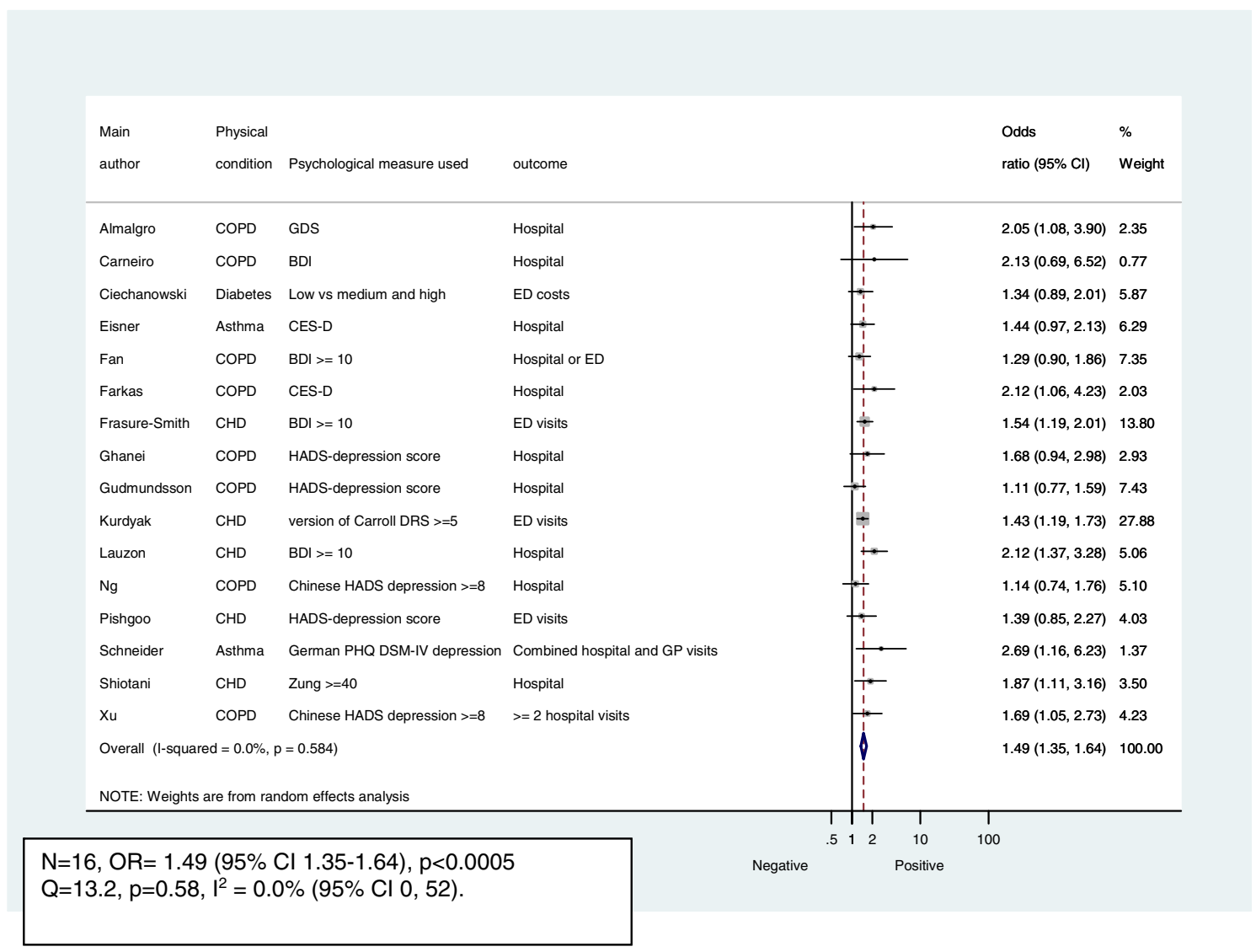

Fig. 2. Forest plot demonstrating associations between depression and subsequent urgent healthcare utilisation.

Our review has some weaknesses. First, by limiting our review to four LTCs of interest, we recognise that our findings may not be generalisable to people with all long term conditions. Second, we used individual researchers to identify papers and extract data. We did not use double data extraction where 2 researchers work independently and then compare their findings, which has been recommended [48]. We recognise this feature may have reduced the reliability of our review, though with $97 \%$ agreement between researchers working independently, we do not consider this methodological weakness undermines our findings. Third, we rated studies using a quality scoring system that categorised studies according to the number of weak characteristics. Presenting an overall quality score in this way assumes that different methodological weaknesses have equal weight, an assumption that lacks empirical support. For completeness, we have included details of the performance of studies on each methodological criterion for each study, to enable readers to interpret quality for themselves. Finally, our analyses revealed no statistically significant difference in effect of depression on urgent healthcare use across different types of urgent healthcare, though some of these differences could be considered clinically significant; range of OR across different types of urgent healthcare $=1.26$ to $2.69(\mathrm{p}=.41)$ and across different LTCs $=1.34$ to $1.76,(p=.76)$. The number of studies involved in these analyses was quite small and the lack of statistical significance may have been due to a lack of statistical power in these analyses.

We interpret our findings as indicating that depression in patients with LTCs is associated with increased use of urgent healthcare. It has previously been shown that depression is associated with increased healthcare costs among patients in primary care systems $[16,49,50]$. Depression is associated with a range of lifestyle risk factors for long term conditions, including increased likelihood of smoking and less adherence to diet, exercise and medication. Whilst these offer plausible potential mechanisms, none have been proven to account for the association with increased urgent healthcare use.

Despite such plausible mechanism by which depression could contribute to the use of urgent healthcare, most studies that controlled for other covariates that included the severity of the LTC showed that the strength of the association became small and non-significant. This could indicate that the effects of depression were confounded by the severity of the LTC. These multivariate findings should be interpreted with caution however because i) only a small minority ( 3 studies) conducted multivariable finding that could be pooled and it cannot be assumed that the same would have been found had other studies made similar controls. ii) A number of covariates in addition to severity of LTC were controlled in each of the multivariable analyses, that could have contributed a confounding effect, including age, sex, smoking and other comorbidities, and iii) depression can also predict worse performance on functional measures of disease severity (used in 2 of the 3 studies we identified that controlled for disease severity) due to the presence of fatigue and lack of motivation [51]. Consequently, our findings are also consistent, with the interpretation that the association of depression with urgent healthcare use was mediated by impaired performance on the measures of disease severity. Either way our findings indicate that the associations of depression with use of urgent healthcare may not be directly causal. Consequently reductions in healthcare use following treatment of depression cannot be assumed from our findings but require assessment through appropriate randomised controlled trials.

Our review has revealed weaknesses in the literature. All of the studies included use brief standardised assessments to identify people with depression or to rate its severity, rather than rely on more robust research interviews. This is likely to mean that many so-called depressed individuals have raised symptoms of depression but would not meet diagnostic criteria for depression according to DSM or ICD criteria. The 
Table 2

Main findings of studies included in the review

\begin{tabular}{|c|c|c|c|}
\hline Author and date & Univariate findings & Factors controlled & Multivariate findings \\
\hline Fan et al. 2007 & $\begin{array}{l}\text { Patients hospitalised or that had ED visit for } \\
\text { COPD were slightly more likely to be depressed } \\
\text { at baseline ( } 29.9 \% \text { versus } 24.8 \% \text { in } \\
\text { non-depressed, } p=.16\end{array}$ & $\begin{array}{l}\text { Adjusted for sex, COPD severity, previous ad- } \\
\text { missions, co-morbidity score }\end{array}$ & $\begin{array}{l}\text { States BDI score }>10 \text { not associated with } \\
\text { hospitalisation in adjusted analyses }\end{array}$ \\
\hline Eisner et al. 2005 & $\begin{array}{l}\text { Depression did not predict ED visits }(\mathrm{HR}=1.36 \text {, } \\
\mathrm{p}=.12) \\
\text { Trend for depression to predict hospitalisation } \\
(\mathrm{HR}=1.34, \mathrm{p}=.06)\end{array}$ & Age, sex, race, education and smoking & $\begin{array}{l}\text { Depression did not predict ED visits (HR, } \\
1.20 ; \mathrm{p}=.36) \text {. } \\
\text { Depression did not predict hospitalisation } \\
(\mathrm{HR}, 1.34 ; \mathrm{p}=.06) .\end{array}$ \\
\hline Schneider et al. 2008 & $\begin{array}{l}\text { Depression predicted hospitalisation (OR, } 6.1 \text {, } \\
\mathrm{p}=.011 \text { ) but not emergency GP visits (OR }=1.7 \\
\mathrm{p}=.30)\end{array}$ & $\begin{array}{l}\text { Medication guideline adherence, smoking, age } \\
\text { and sex }\end{array}$ & $\begin{array}{l}\text { Depressive disorder predicted } \\
\text { hospitalisation }(\mathrm{p}=.009)\end{array}$ \\
\hline Ng et al. 2007 & $\begin{array}{l}61 \% \text { depressed patients had } \geq 1 \text { urgent } \\
\text { hospitalisation } \\
57.8 \% \text { non-depressed had } \geq 1 \text { urgent } \\
\text { hospitalisation, } p=.31\end{array}$ & Age, sex, FVC, previous admissions SGRQ., & $\begin{array}{l}\text { Depression did not predict hospitalisation } \\
(\mathrm{HR}=0.93(0.68-1.28)\end{array}$ \\
\hline Almagro et al. 2005 & $\begin{array}{l}\text { Readmitted patients showed higher baseline } \\
\text { depression scores ( } 5 \text { vs } 3.7, p=<.05 \text { ) than those } \\
\text { who were not readmitted }\end{array}$ & Age, sex $\mathrm{FEV}_{1}$, comorbidty, social support & $\begin{array}{l}\text { Depression not independent predictor of } \\
\text { readmission. }\end{array}$ \\
\hline Gudmundsson et al. 2006 & $\begin{array}{l}\text { Hospitalised and non-hospitalised patients had } \\
\text { similar baseline depression scores ( } 5.6 \text { versus } \\
5.4, \mathrm{p}=.63 \text { ) }\end{array}$ & Age, smoking status, $\mathrm{FEV}_{1}$, & Depression HR=1.09 $(0.8-1.51)$ \\
\hline Lauzon et al. 2003 & $\begin{array}{l}\text { Patients depressed at baseline had higher rates } \\
\text { of hospitalisation because of any cardiac } \\
\text { complication ( } 30.9 \% \text { versus } 17.5 \% \text { ) }\end{array}$ & $\begin{array}{l}\text { Age, previous MI, anterior MI, diabetes, hyper- } \\
\text { tension, smoking, sex, previous angina }\end{array}$ & $\begin{array}{l}\text { Readmission due to cardiac complications } \\
\text { higher in depressed patients }[\mathrm{HR}=1.4 \\
(1.05-1.86)]\end{array}$ \\
\hline Frasure-Smith et al. 2000 & $\begin{array}{l}\text { Authors unable to confirm all hospitalisations } \\
\text { were urgent . } \\
\text { Depressed patients had greater mean ED visits } \\
\text { ( } 1.3 \text { versus } 0.9, p<.0001 \text { ) }\end{array}$ & & $\begin{array}{l}\text { Findings of multivariate analysis not } \\
\text { presented for urgent healthcare utilisation }\end{array}$ \\
\hline Kurdyak et al. 2008 & $\begin{array}{l}\text { Author unable to confirm that all hospital } \\
\text { admissions were urgent. } \\
\text { Depressed patients had significantly more ED } \\
\text { visits (mean }=1.7 \text { versus } 1.3, \mathrm{p}<.001 \text { ) }\end{array}$ & $\begin{array}{l}\text { Age, sex, income, co-orbidity, GRACE score, } \\
\text { drugs at discharge, cardiac interventions and } \\
\text { symptom burden }\end{array}$ & $\begin{array}{l}\text { Adjusted risk for ED visits not presented. } \\
\text { Approx adjusted risk for depression } \\
\text { predicting ED visits read from figure }=1.1 \text {. }\end{array}$ \\
\hline Xu et al. 2008 & $\begin{array}{l}\text { More depressed patients were hospitalised for } \\
\text { COPD exacerbations ( } 29.5 \% \text { versus } 19.8 \% \text { ) }\end{array}$ & $\begin{array}{l}\text { Age, sex, marital, educational and employment } \\
\text { status, smoking, } \mathrm{FEV}_{1} \text {, dyspnea, 6-min walk, so- } \\
\text { cial support, self efficacy, co morbidities, hospi- } \\
\text { tal type, drug and } \mathrm{O}_{2} \text { use, previous } \\
\text { hospitalisations }\end{array}$ & $\begin{array}{l}\text { Adjusted Incidence Rate Ratio for probable } \\
\text { depression predicting hospitalisation }=1.72 \\
(1.04-2.85)\end{array}$ \\
\hline Shiotani et al. 2002 & $\begin{array}{l}\text { Incidence of cardiac event related readmission } \\
\text { was significantly higher in depressed patients } \\
\text { ( } 7.8 \% \text { versus } 4.3 \%, p=.018) \text {. }\end{array}$ & - & $\begin{array}{l}\text { Multivariate results not presented for cardiac } \\
\text { event related readmissions }\end{array}$ \\
\hline Ciechanowski et al. 2000 & $\begin{array}{l}\text { ED visit costs: } \\
\text { Low depression group }=81(375) \\
\text { Medium depression group }=128(479) \\
\text { High depression group }=185(548)\end{array}$ & 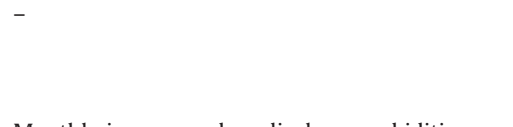 & Not reported for urgent healthcare utilisation \\
\hline Ghanei et al. 2007 & $\begin{array}{l}\text { Rehospitalised patients had higher depression } \\
\text { scores than those not rehospitalised ( } 12 \text { versus } \\
11, \mathrm{p}=.039 \text { ) }\end{array}$ & Monthly income and medical co-morbidities & $\begin{array}{l}\text { Depression is an independent predictor of } \\
\text { urgent readmission (risk ratio }=0.31, \mathrm{p}= \\
.012 \text { ) after controlling for monthly income } \\
\text { and medical co-morbidities }\end{array}$ \\
\hline Carneiro et al. 2010 & $\begin{array}{l}\text { Number of readmission correlated with } \\
\text { depression score }(p=.09)\end{array}$ & - & Not reported \\
\hline Farkas et al. 2010 & $\begin{array}{l}\text { Depression score was higher for hospitalised } \\
\text { compared to non-hospitalised [15 (sd=11) } \\
\text { versus } 11(\mathrm{sd}=9)]\end{array}$ & 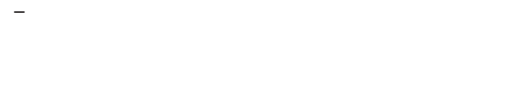 & $\begin{array}{l}\text { Depression not entered into the multivariate } \\
\text { analyses }\end{array}$ \\
\hline Pishgoo, 2011 & $\begin{array}{l}\text { Baseline depression score } 5.7 \text { among those with } \\
\text { ED visits versus } 5.1 \text { in those without, } \mathrm{p}=.22\end{array}$ & $\begin{array}{l}\text { Sex, angina grade, anxiety and somatic } \\
\text { comorbidity score contributed entered into final } \\
\text { model }\end{array}$ & $\begin{array}{l}\text { Sex, angina grade, anxiety and somatic } \\
\text { comorbidity score contributed significantly } \\
\text { to the final model. Depression was not } \\
\text { entered into the model as univariate } \\
\text { findings were non-significant }\end{array}$ \\
\hline
\end{tabular}

Abbreviations

BDI Beck Depression Inventory.

COPD chronic obstructive pulmonary disease.

ED emergency department.

$\mathrm{FEV}_{1} \quad$ forced expiratory volume in $1 \mathrm{~s}$.

FVC forced vital capacity.

GRACE global registry of acute coronary events.

HR hazards ratio.

OR odds ratio.

SGRQ St Georges Respiratory Questionnaire.

only study that identified subjects with depression that was comparable to DSM-IV depression (ref Schneider) showed the largest effect on urgent hospitalisation. This might indicate that the widespread use of brief assessments has resulted in an under-estimation of the strength of the association between depression and urgent hospitalisation.
Furthermore, few studies conducted multivariable analysis to control for important potential confounding factors.

Our findings have a number of implications for clinical practice. Though our findings suggest that treating depression among LTC patients may not reduce use of urgent healthcare, we consider that 
Table 3

Quality assessment

\begin{tabular}{|c|c|c|c|c|c|c|c|c|c|c|}
\hline Details of Papers & $\begin{array}{l}\text { Selection } \\
\text { bias }\end{array}$ & Design & Confounding & Blinding & $\begin{array}{l}\text { Data } \\
\text { collection }\end{array}$ & $\begin{array}{l}\text { Drop } \\
\text { outs }\end{array}$ & $\begin{array}{l}\text { Global } \\
\text { rating }\end{array}$ & $\begin{array}{l}\text { Discrepancy } \\
\text { between reviewers }\end{array}$ & Reasons for discrepancy & $\begin{array}{l}\text { Final } \\
\text { rating }\end{array}$ \\
\hline Almagro et al. 2006 & 2 & 2 & 1 & 2 & 1 & 1 & 1 & No & & 1 \\
\hline Carneiro et al. 2010 & 3 & 2 & 3 & 2 & 1 & 1 & 3 & No & & 3 \\
\hline Ciechanowski et al. 2000 & 2 & 2 & 3 & 2 & 1 & 3 & 2 & Yes & Oversight & 3 \\
\hline Eisner et al. 2005 & 2 & 2 & 2 & 2 & 1 & 3 & 2 & No & & 2 \\
\hline Fan et al. 2007. & 3 & 2 & 1 & 2 & 1 & 1 & 3 & Yes & Oversight & 2 \\
\hline Farkas et al. 2010 & 3 & 2 & 3 & 2 & 1 & 3 & 3 & No & Differences in interpretation & 3 \\
\hline Frasure-Smith et al. 2000 & 3 & 2 & 3 & 2 & 1 & 3 & 3 & No & & 3 \\
\hline Ghanei et al. 2007 & 3 & 2 & 2 & 2 & 1 & 3 & 3 & Yes & Differences in interpretation & 3 \\
\hline Gudmundsson et al. 2006 & 3 & 2 & 1 & 2 & 1 & 3 & 3 & No & & 3 \\
\hline Kurdyak et al. 2008 & 3 & 2 & 1 & 2 & 1 & 2 & 2 & Yes & Differences in interpretation & 2 \\
\hline Lauzon et al. 2003 & 3 & 2 & 1 & 2 & 1 & 1 & 2 & Yes & Oversight & 2 \\
\hline Ng et al. 2007 & 2 & 2 & 1 & 2 & 1 & 2 & 1 & No & & 1 \\
\hline Pishgoo et al. 2011 & 3 & 2 & 3 & 2 & 1 & 1 & 3 & No & & 3 \\
\hline Schneider et al. 2008 & 3 & 2 & 2 & 2 & 1 & 2 & 2 & No & & 2 \\
\hline Shiotani et al. 2002 & 3 & 2 & 3 & 2 & 1 & 1 & 3 & Yes & Differences in interpretation & 3 \\
\hline Xu et al. 2008 & 3 & 2 & 1 & 2 & 1 & 1 & 2 & No & & 2 \\
\hline
\end{tabular}

Quality ratings: $1=$ strong, $2=$ moderate, $3=$ weak.

depression treatment in such LTC patients remains important as it has potential to improve health-related quality of life. Furthermore, we have shown that the substantial subgroup of depressed LTCs patients are at significantly increased risk of using expensive urgent and unscheduled healthcare. In other words, irrespective of whether it contributes causally to increased use of urgent healthcare, depression could be assessed using self-rated questionnaires and used as a "red flag" to identify patients with LTCs at high risk of urgent healthcare use, alongside other potential markers of risk of high healthcare use, such as previous use of high urgent healthcare and severity of illness. Depression thus identified could be used to direct interventions, such as telephone follow-up [52], home care [53], or even case management [54], which have been shown to reduce the use of urgent healthcare in previous research.

From a research perspective, further studies are now required to develop and evaluate interventions that reduce the use of urgent healthcare use, and to explore how these interventions perform with different patient groups, with differing LTCs and in various healthcare settings. Trials of novel service innovations or maybe even simple educational interventions are required, that assess the benefits but also the potential problems associated with directing patients at high risk of using urgent healthcare (such as those with depression) to less

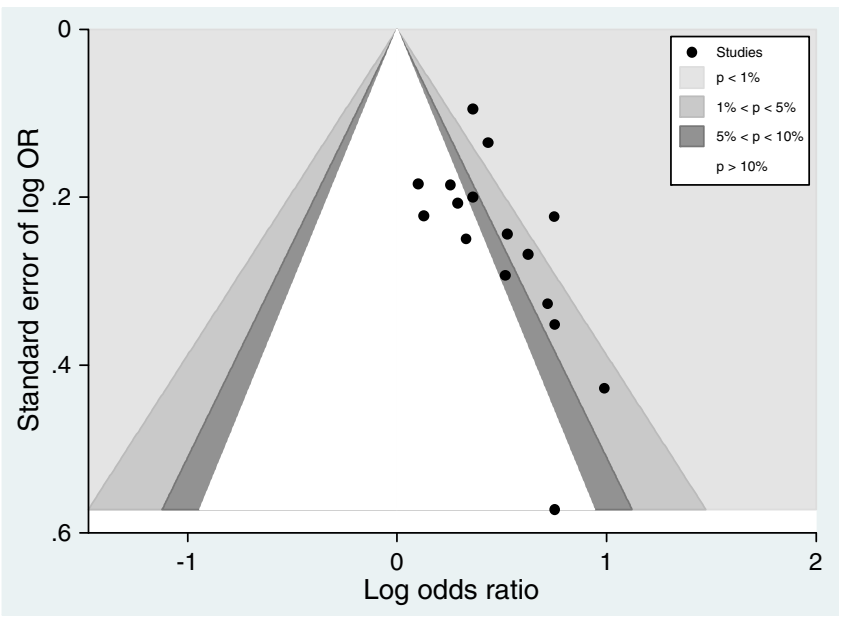

Egger's test:

intercept 1.98 (95\% Cl 0.22 to 3.74$), p=0.03$

Fig. 3. Contour enhanced funnel plot: logs OR versus standard error of log OR. expensive sources of care and support. To date, very few randomised controlled trials have recruited depressed LTC patients, and investigated the impact of treating depression on urgent healthcare use. The methodologies employed and the effects observed have been very mixed $[55,56]$. The extent to which depression causes increased use of urgent healthcare therefore requires further assessment through depression treatment trials in these patient groups.

\section{Disclosure of potential conflicts of interest, activities, relationships and affiliations}

Katon has received honoraria for lectures for Lilly, Wyeth, Forest, Phizer and acts on advisory boards for Lilly, Wyeth.

None of the other authors have conflicts of interests or financial interests to declare.

\section{Sources of funding and support}

This study funded by the National Institute for Health Research (NIHR) under its Programme Grants for Applied Research programme (Grant Reference Number RP-PG-0707-10162), by the University of Manchester (Dickens and McGowan), and the National Institute for Health Research (NIHR) Collaboration for Leadership in Applied Health Research and Care (CLAHRC) for the South West Peninsula (Dickens) known as PenCLAHRC. PenCLAHRC is a collaboration of higher education institutions and NHS organisation in the South West of England.

\section{Disclaimer}

The views expressed in this article are those of the authors and not necessarily those of the NHS, the NIHR or the Department of Health.

\section{Acknowledgments}

We wish to acknowledge the contribution of authors who provided additional information on their studies, namely, R. Benzo, S. Buist, R. Carneiro, D. Davydow, G. Diette, M. Eisner, V. Fan, J Farkas-Lainscak, N. Frasure-Smith, S. Grace, C. Greaves, G. Gudmundsson, A. Kaptein, P. Kurdyak, S. Mallik, C. Mancuso, R. Mayou, M. Miller, T. Ng, L. Pilote, T. Rutledge, A Schneider, J. Spertus, F. Stiefel, J. Strik, M. Sullivan, C. Tsai, J. Vega Reyes.

We acknowledge the advice given by Dr. Jaime Peters on the detailed analysis and interpretation of publication bias. 


\section{Appendix A. Supplementary data}

Supplementary data to this article can be found online at http:// dx.doi.org/10.1016/j.jpsychores.2012.08.018.

\section{References}

[1] Office of National Statistics. General household survey 2005: overview report; 2006.

[2] U.S.Department of Health and Human Service. The burden of chronic diseases and their risk factors; 2010.

[3] Kung HC, Hoyert DL, Xu J, Murphy SL. Deaths: final data for 2005. Natl Vital Stat Rep 2008;56:1-120.

[4] Ogden CL, Carroll MD, McDowell MA, Flegal KM. Obesity among adults in the United States - no statistically significant chance since 2003-2004. NCHS Data Brief; 2007. p. 1-8.

[5] WHO. Global status report on non-communicable diseases 2010; 2010.

[6] U.S.Department of Health, Services Human. Health, United States, 2006, with chartbook on trends in the health of Americans. DHHS Pub. No. 2006-1232; 2006; 2006.

[7] Magid DJ, Houry D, Ellis J, Lyons E, Rumsfeld JS. Health-related quality of life predicts emergency department utilization for patients with asthma. Ann Emerg Med 2004; $43: 551-7$.

[8] Tsai CL, Griswold SK, Clark S, Camargo CA. Factors associated with frequency of emergency department visits for chronic obstructive pulmonary disease exacerbation. J Gen Intern Med 2007;22:799-804.

[9] Williams AE, Lloyd AC, Watson L, Rabe KF. Cost of scheduled and unscheduled asthma management in seven European Union countries. Eur Respir Rev 2006;15:4-9.

[10] Mancuso CA, Rincon M, McCulloch CE, Charlson ME. Self-efficacy, depressive symptoms, and patients' expectations predict outcomes in asthma. Med Care 2001;39:1326-38.

[11] Schneider A, Lowe B, Meyer FJ, Biessecker K, Joos S, Szecsenyi J. Depression and panic disorder as predictors of health outcomes for patients with asthma in primary care. Respir Med 2008;102:359-66.

[12] Moussavi S, Chatterji S, Verdes E, Tandon A, Patel V, Ustun B. Depression, chronic diseases, and decrements in health: results from the World Health Surveys. Lancet 2007;370:851-8.

[13] Stein MB, Cox BJ, Afifi TO, Belik SL, Sareen J. Does co-morbid depressive illness magnify the impact of chronic physical illness? A population-based perspective. Psychol Med 2006;36:587-96.

[14] Effective public health practice project. Quality assessment tool for quantitative studies dictionary; 2009.

[15] Effective public health practice project. Quality assessment tool for quantitative studies; 2011.

[16] Katon WJ, Lin E, Russo J, Unutzer J. Increased medical costs of a population-based sample of depressed elderly patients. Arch Gen Psychiatry 2003;60:897-903.

[17] Keene J, Rodriguez J. Are mental health problems associated with use of accident and emergency and health-related harm? Eur J Public Health 2007;17:387-93.

[18] Williams ER, Guthrie E, kway-Jones K, James M, Tomenson B, Eastham J, McNally D. Psychiatric status, somatisation, and health care utilization of frequent attenders at the emergency department: a comparison with routine attenders. J Psychosom Res 2001;50:161-7.

[19] Nichols L, Barton PL, Glazner J, McCollum M. Diabetes, minor depression and health care utilization and expenditures: a retrospective database study. Cost Eff Resour Alloc 2007;5:4.

[20] Ng TP, Niti M, Tan WC, Cao Z, Ong KC, Eng P. Depressive symptoms and chronic obstructive pulmonary disease: effect on mortality, hospital readmission, symptom burden, functional status, and quality of life. Arch Intern Med 2007;167:60-7.

[21] Fan VS, Ramsey SD, Giardino ND, Make BJ, Emery CF, Diaz PT, Benditt JO, Mosenifar Z, McKenna Jr R, Curtis JL, Fishman AP, Martinez FJ. Sex, depression, and risk of hospitalization and mortality in chronic obstructive pulmonary disease. Arch Intern Med 2007;167:2345-53.

[22] Global status report on non-communicable disease 2010. WHO, editor. 2011.

[23] Nawar EW, Niska RW, Xu J. National Hospital Ambulatory Medical Care Survey: 2005 emergency department summary. 386, 1-31. 29-6-2007. Adv Data.

[24] Damush TM, Smith DM, Perkins AJ, Dexter PR, Smith F. Risk factors for nonelective hospitalization in frail and older adult, inner-city outpatients. Gerontologist 2004;44:68-75

[25] Lipsey M, Wilson D. Practical meta-analysis. London: Sage Publications; 2001.

[26] Systematic reviews in health care: meta analysis in context. 2 ed.London: BMJ Books; 2011.

[27] Higgins JP, Thompson SG, Deeks JJ, Altman DG. Measuring inconsistency in meta-analyses. BMJ 2003;327:557-60.

[28] Moreno S, Sutton A, Ades A, Stanley T, Abrams K, Peters J, et al. Assessment of regression-based methods to adjust for publication bias through a comprehensive simulation study. BMC Med Res Methodol 2009;9.
[29] Egger M, Davey SG, Schneider M, Minder C. Bias in meta-analysis detected by a simple, graphical test. BMJ 1997;315:629-34.

[30] Egger M, Davey Smith G, Altman DG. Systematic reviews in health care: meta-analysis in context. London: BMJ Publishing; 2010.

[31] Peters JL, Sutton AJ, Jones DR, Abrams KR, Rushton L. Comparison of two methods to detect publication bias in meta-analysis. JAMA 2006;295:676-80.

[32] Rosenthal R. Meta analytic procedures for social research. London: Sage; 1991.

[33] Duval S. Trim and fill: a simple funnel-plot-based method of testing and adjusting for publication bias in meta-analysis; 2000.

[34] Ciechanowski PS, Katon WJ, Russo JE. Depression and diabetes: impact of depressive symptoms on adherence, function, and costs. Arch Intern Med 2000;160: 3278-85.

[35] Eisner MD, Katz PP, Lactao G, Iribarren C. Impact of depressive symptoms on adult asthma outcomes. Ann Allergy Asthma Immunol 2005;94:566-74.

[36] Gudmundsson G, Gislason T, Janson C, Lindberg E, Suppli UC, Brondum E, Nieminen MM, Aine T, Hallin R, Bakke P. Depression, anxiety and health status after hospitalisation for COPD: a multicentre study in the Nordic countries. Respir Med 2006;100:87-93.

[37] Almagro P, Barreiro B, Ochoa de EA, Quintana S, Rodriguez CM, Heredia JL, Garau J. Risk factors for hospital readmission in patients with chronic obstructive pulmonary disease. Respiration 2006;73:311-7.

[38] Lauzon C, Beck CA, Huynh T, Dion D, Racine N, Carignan S, Diodati JG, Charbonneau F, Dupuis R, Pilote L. Depression and prognosis following hospital admission because of acute myocardial infarction. CMAJ 2003;168:547-52.

[39] Frasure-Smith N, Lesperance F, Gravel G, Masson A, Juneau M, Talajic M, Brondum E Bourassa MG. Depression and health-care costs during the first year following myocardial infarction. J Psychosom Res 2000;48:471-8.

[40] Xu W, Collet JP, Shapiro S, Lin Y, Yang T, Platt RW, Wang C, Bourbeau J. Independent effect of depression and anxiety on chronic obstructive pulmonary disease exacerbations and hospitalizations. Am J Respir Crit Care Med 2008;178:913-20.

[41] Shiotani I, Sato H, Kinjo K, Nakatani D, Mizuno H, Ohnishi Y, Hishida E, Kijima Y Hori M, Sato H. Depressive symptoms predict 12-month prognosis in elderly patients with acute myocardial infarction. J Cardiovasc Risk 2002:9:153-60.

[42] Kurdyak PA, Gnam WH, Goering P, Chong A, Alter DA. The relationship between depressive symptoms, health service consumption, and prognosis after acute myocardial infarction: a prospective cohort study. BMC Health Serv Res 2008;8:200.

[43] Farkas J, Kosnik M, Flezar M, Suskovic S, Lainscak M. Self-rated health predicts acute exacerbations and hospitalisations in patients with COPD. Chest 2010;138:323-30.

44] Carneiro R, Sousa C, Pinto A, Almeida F, Olivera J, Rocha N. Risk factors for readmission after hospital discharge in chronnic obstructive pulmonary disease. Rev Port Pneumol 2010;16:759-77.

[45] Ghanei M, Aslani J, Aziz Abadi-Farahani M, Assari S, Saadat S. Logistic regression model to predict chronic obstructive pulmonary disease exacerbation. Arch Med Sci 2007;3:360-6.

[46] Pishgoo B. A novel prediction model for all cause emergency department visits in ischaemic heart disease. JRMS 2011;16:262-8.

[47] Sterne JA, Sutton AJ, Ioannidis JP, Terrin N, Jones DR, Lau J, Carpenter J, Rucker G Harbord RM, Schmid CH, Tetzlaff J, Deeks JJ, Peters J, Macaskill P, Schwarzer G, Duval S, Altman DG, Moher D, Higgins JP. Recommendations for examining and interpreting funnel plot asymmetry in meta-analyses of randomised controlled trials. BMJ 2011;343:d4002.

[48] Cochrane handbook for systematic reviews of interventions version 5.0.2. The Cochrane Collaboration; 2009.

[49] Simon GE, Katon WJ, Lin EH, Ludman E, Vonkorff M, Ciechanowski P, Young BA Diabetes complications and depression as predictors of health service costs. Gen Hosp Psychiatry 2005;27:344-51.

[50] Unutzer J, Patrick DL, Simon G, Grembowski D, Walker E, Rutter C, Katon W. Depressive symptoms and the cost of health services in HMO patients aged 65 years and older. A 4-year prospective study. JAMA 1997;277:1618-23.

[51] Lavoie KL, Fleet RP. The impact of depression on the course and outcome of coronary artery disease: review for cardiologists. [Review] [96 refs]Can J Cardiol 2000;16: 653-62.

[52] Wong KW, Wong FK, Chan MF. Effects of nurse-initiated telephone follow-up on self-efficacy among patients with chronic obstructive pulmonary disease. J Adv Nurs 2005:49:210-22.

[53] Farrero E, Escarrabill J, Prats E, Maderal M, Manresa F. Impact of a hospital-based home-care program on the management of COPD patients receiving long-term oxygen therapy. Chest 2001;119:364-9.

[54] Bourbeau J, Collet JP, Schwartzman K, Ducruet T, Nault D, Bradley C. Economic benefits of self-management education in COPD. Chest 2006;130:1704-11.

[55] Oldridge N, Furlong W, Feeny D, Torrance G, Guyatt G, Crowe J, Jones N. Economic evaluation of cardiac rehabilitation soon after acute myocardial infarction. Am J Cardiol 1993;72:154-61.

[56] Simon GE, Katon WJ, Lin EH, Rutter C, Manning WG, Von KM, Ciechanowski P, Ludman EJ, Young BA. Cost-effectiveness of systematic depression treatment among people with diabetes mellitus. Arch Gen Psychiatry 2007;64:65-72. 